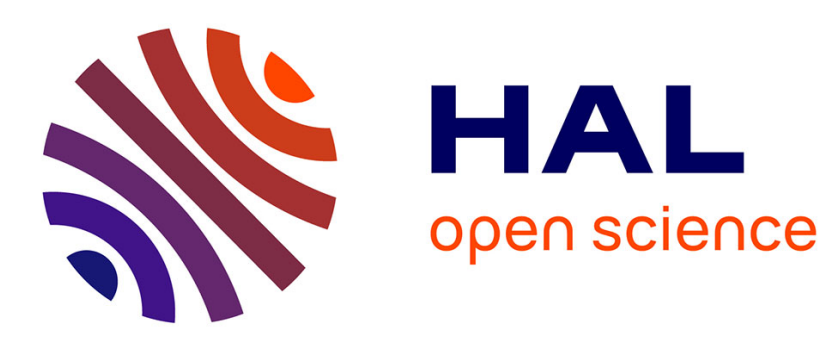

\title{
Taking multiple exposure into account can improve assessment of chemical risks
}

Frédéric Clerc, Nicolas Jean Hyacinthe Bertrand, Bénédicte La Rocca

\section{To cite this version:}

Frédéric Clerc, Nicolas Jean Hyacinthe Bertrand, Bénédicte La Rocca. Taking multiple exposure into account can improve assessment of chemical risks. Annals of Work Exposures and Health, In press, 10.1093/annweh/wxx086 . hal-01655262

\section{HAL Id: hal-01655262 \\ https://hal.science/hal-01655262}

Submitted on 4 Dec 2017

HAL is a multi-disciplinary open access archive for the deposit and dissemination of scientific research documents, whether they are published or not. The documents may come from teaching and research institutions in France or abroad, or from public or private research centers.
L'archive ouverte pluridisciplinaire HAL, est destinée au dépôt et à la diffusion de documents scientifiques de niveau recherche, publiés ou non, émanant des établissements d'enseignement et de recherche français ou étrangers, des laboratoires publics ou privés. 


\title{
Taking multiple exposure into account can improve assessment of chemical risks
}

\author{
F. Clerc, N. Bertrand, B. La Rocca \\ INRS - rue du Morvan, 54500 Vandœuvre-lès-Nancy, France
}

\begin{abstract}
During work, operators may be exposed to several chemicals simultaneously. Most exposure assessment approaches only determine exposure levels for each substance individually. However, such individual-substance approaches may not correctly estimate the toxicity of "cocktails" of chemicals, as the toxicity of a cocktail may differ from the toxicity of substances on their own. This study presents an approach that can better take into account multiple exposure when assessing chemical risks. Almost 30,000 work situations, monitored between 2005 and 2014 and recorded in two French databases, were analysed using MiXie software. The algorithms employed in MiXie can identify toxicological classes associated with several substances, based on the additivity of the selected effects of each substance. The results of our retrospective analysis show that MiXie was able to identify almost $20 \%$ more potentially hazardous situations than identified using a single-substance approach. It therefore appears essential to review the ways in which multiple exposure is taken into account during risk assessment.
\end{abstract}

\section{Introduction}

Most workers are exposed to several substances in the workplace and the consideration of these complex situations in risk-assessment needs to be improved. Multiple exposure may result from simultaneous exposure to several chemical substances or from successive exposures leading to the simultaneous presence of these substances in the organism. The impacts of multiple exposure on worker's health is difficult to address and is therefore rarely taken into account in risk assessment.

Several risk-assessment methods have been proposed that rank the risks encountered in a singlesubstance approach [1] [2] [3] [4]. The results of these assessments can be used to establish priorities in the preventive actions to be implemented. When an assessment identifies specific risks, or if regulatory requirements demand it, atmospheric concentrations must be regularly measured to determine the levels of dangerous chemicals. When a work situation involves a number of substances, several separate measurement campaigns must be performed. The chemical risk is therefore assessed substance by substance, and does not take into account the combined toxicological effects of the cocktail of chemicals. Pending the availability of toxicological or epidemiological data on mixture effects, decision-making tools such as MiXie have been developed to evaluate these impacts.

In Canada, the Institut de recherche Robert-Sauvé en Santé et en sécurité du Travail (IRSST) and University of Montréal created the MiXie webpage in order to estimate the health-effects of cocktails of substances by applying a principle of additivity of effects [5] [6]. MiXie can be used to identify potential toxicological effects by comparing the concentrations of the different substances to their individual OELV and then using this data to determine an exposure index for a particular cocktail of 
substances, termed the "Mixture" in Mixie. The Mixie software was recently adapted by the INRS for use with French OEL values [7].

In this study, the algorithms in the MiXie software were adapted for use with large datasets, such as data extracted from COLCHIC and SCOLA. The objective was to compare the results of riskassessments performed by single- and multiple-substance approaches.

\section{Methods}

2.1. Evaluation of the potential risks related to multiple exposure using MiXie software Given the high number of substances available on the market, it would be very difficult to determine the effects of all possible combinations of substances by performing experimental toxicology tests or epidemiological studies. MiXie, a decision-making tool available on the web, estimates the risk associated with exposure to several chemical substances, with the additivity of the effects as a hypothesis, supposing that substances causing the same harmful effects would additively increase the risks to workers. In MiXie, the effects identified for each substance are categorized into 32 toxicological classes, for example "central nervous system involvement", "liver involvement", or "embryonic or fœtal disorders". For a given mixture, the toxicological classes shared by several chemical substances are highlighted and, for each common class, an exposure index is calculated (EI = exposure concentration measured / OELV). The MiXie algorithm is sensitive to the OELV adopted in each country as it uses the OELV to determine the exposure index for a mixture. Only effects appearing within five-times the OELV for studies in humans, and one-hundred-times the OELV for animal studies, are taken into account. The toxicological database for the Canadian version of MiXie contains over 700 substances, 347 of which have an OELV assigned to them in France. The toxicological classes defined in the MiXie algorithms are linked not to regulatory considerations, but instead to the scientific literature. Thus, the "cancer" class, for example, is associated with several substances in MiXie, some of which are not considered carcinogenic in CLP regulation [8].

2.2. Extraction of measurement data and creation of "work situations"

All atmospheric concentration measurements made in line with regulations on French territory are, in principle, transmitted to the French Research and Safety Institute for the Prevention of Occupational Accidents and Diseases (INRS), where they are then entered into the SCOLA database [9]. Likewise, all atmospheric concentration measurements conducted by the interregional chemical laboratories of the French regional health insurance funds or by INRS laboratories as part of preventive programmes, prospection, or support for epidemiological studies, are archived in the COLCHIC database [10]. The COLCHIC and SCOLA databases share a common technical structure and comparisons of exposure levels between the two databases are therefore possible [11]. In addition, as the data are derived from different sources, there are no double-entries in the two databases.

For the period 1984-2017, the COLCHIC and SCOLA databases contain records of over 922,000 and 256,000 concentration measurements taken in over 26,000 and 7,300 companies, respectively. In both cases, the concentrations recorded in the database are associated with a chemical substance, a company, an activity sector and a task. This information is supplied using codes related either to specific reference data (e.g., the task performed by the operator) or to international references (the NACE code for the company' sector of activity. From all the data contained in the two databases, only individual samples corresponding to sampling durations of between 60 and 600 minutes were extracted. Moreover, only data recorded during a maximum of the last 10 years were retained (2005 
- 2014 for COLCHIC and 2007 - 2014 for SCOLA). These data were grouped into so-called work situations, in which samples were collected in the same company, for the same working task and during the same month. For example, a work situation in company $X$ might consist of 10 measurements of substance A, 5 measurements of substance $B$ and 3 measurements of substance $C$, made during for the same task during the same month. The measurements for any given work situation are assumed to be representative of the exposure of a specific group of workers, performing the same task during the same period.

2.3. Assessing exposure for different situations

For each situation, maximum El values $\left(E I_{\max }\right)$ were calculated for each substance. A representative situation is presented in Table 1 . Three volatile organic compounds were sampled: toluene -3 measurements; methylethylcetone -2 measurements; and xylene -3 measurements.

Table 1. A representative multiple-exposure situation and the corresponding $\mathrm{El}_{\max }$ calculations

For each class of toxicological effects triggered, the $\sum \mathrm{El}$ value was obtained by summing the $\mathrm{El}_{\max }$ values calculated for each individual substance in the mixture. The $\Sigma \mathrm{El}$ values of our representative situation are listed in Table 2.

Table 2. Exposure index of the mixture ( $(E I)$ calculated for each class of toxicological effect triggered

\section{Results}

3.1. Overview

Of the 38,666 work situations identified in the two databases over the last decade, 13,629 were related to multiple exposures, i.e. situations in which workers were simultaneously exposed to at least two of the substances listed in MiXie. Among the 13,629 multiple exposure situations, 2,906 (21\%) were considered "poorly controlled" for at least one class of toxicological effects according to the MiXie analysis. For some tasks, the proportion of "poorly controlled" situations relative to the total number of situations exceeded $15 \%$, for example mixing (17\%) and smelting (16\%) (Table 3).

Table 3. Overview of work-situations in the COLCHIC and SCOLA databases for the period 2005-2014

The classes of toxicological effects involved in poorly controlled situations were most frequently eye involvement (16\% of situations), upper respiratory tract involvement (16\%), cancer $(16 \%)$, skin disorders (14\%), lower respiratory tract involvement (15\%) and central nervous system involvement (7\%). The other 26 classes together represented only $16 \%$ of situations. Details of the classes of effects activated in different situations are shown in Figure 1, where we observe, for example, that the "upper respiratory tract involvement" class was activated in $20 \%$ of machining situations.

Figure 1. Toxicological classes activated in poorly controlled situations during different tasks.

\subsection{Mixtures of substances}

Using a Bayesian network [12] [13], 25 "typical mixtures", composed of between 2 and 5 substances, were identified. However, situations in which every substance contained in a typical mixture was sampled were rarely listed in the databases. For this reason, it is considered that a mixture was observed when at least half of the substances that comprise it were present. Thus, among the 2,906 "poorly controlled" situations, 6 mixtures were most frequently observed: these mixtures were encountered in over $3 \%$ of all situations (Table 4). 
In Table 4, the frequency of observation of mixtures of substances in "poorly controlled" situations is shown for each task performed. Thus, the silica-related mixture composed of cristobalite, respirable dusts, quartz and tridymite was identified in $16 \%$ of the 623 poorly controlled machining situations activating at least one toxicological class. This particular silica-related mixture corresponds to a French regulatory definition. In some situations, several mixtures were observed and the sum of the values may therefore exceed $100 \%$ in a single situation, for example in the case of tasks performed as part of building and public works. For tasks related to substance mixing, the toxicity class "effects on the central nervous system" was activated in $12 \%$ of situations, compared to $5 \%$ on average for all tasks. Activation of this class correlated with the frequent and specific presence of mixture VOC-2 (2phenylpropene; butyl acrylate; acetone; methyl methacrylate; and styrene). It can also be seen that smelting tasks were frequently associated with effects on the lower airways: reported in $27 \%$ of situations where smelting is performed compared to only $17 \%$ of situations on average for all tasks.

Table 4. Typical mixtures of substances, their toxicological effects and the frequency with which they were associated with various tasks (Frequency $=$ the number of poorly controlled situations involving the mixture divided by the total number of poorly controlled situations).

\subsection{Non-compliance with OELV}

Among the 13,629 multiple exposure situations, 2,906 "poorly controlled" situations were identified by the MiXie algorithms. Among these, 2,442 involved exposure of workers to at least one substance at a concentration exceeding its OELV. Therefore, 464 of the poorly controlled situations (i.e $16 \%$ ) would not have been identified on the basis of the OELV alone: no exposure values exceed OELV but the $\sum$ El was greater than 1 . This is a false negative (Figure 2).

Figure 2. $16 \%$ of poorly controlled situations involved exposure of workers to mixtures at concentrations lower than the OELV of the individual components. These situations cannot be identified without the use of multiple-exposure risk assessment. In the table, " $n b$ of situations" refers to the total number of work situations where the task was performed.

Most of the poorly controlled situations related to exposure to mixtures were associated with tasks in manufacturing industries-machining, preparation of surfaces, mixing and bottling-where the number of false negatives exceeded $20 \%$. This is also the case for printing, textile, waste and steel working, though the number of situations here was smaller. The ratio of the number of poorly controlled situations, that cannot be identified from the OELV of single substances, to the total number of situations recorded in the databases helps to more clearly identify tasks associated with the highest risks due to multiple exposures.

\section{Discussion}

The multiple substance approach revealed 464 situations (i.e. $16 \%$ of situations) in which no OELV was exceeded but where the $\sum \mathrm{El}$ value was greater than 1 for one or more toxicological classes. These situations therefore pose potential health risks to the workers. A single substance approach, based only on the OELV of each substance, would not have identified any risk in these situations.

Although very useful, the MiXie algorithms have some deficiencies. Exposure to mixtures may give rise to a range of phenomena that may affect the toxicity of substances examined separately. The additivity of effects is the default hypothesis used in MiXie France. Infra-additivity refers to a 
situation in which the mixture is less toxic than the individual substances that comprise it. Finally, supra-additivity corresponds to a situation in which synergistic effects occur, meaning that the mixture is more toxic than the sum of the individual toxicities of the substances that comprise it. A more extensive analysis of the literature on mixtures will be necessary to identify all potential interactions between substances, instead of applying additivity in all cases.

The COLCHIC and SCOLA databases are not fully representative of all work-related exposure situations in France. For example, measurements in the databases were not collected by probabilistic sampling but were instead made for either insurance purposes (COLCHIC) or regulation purposes (SCOLA). The practices adopted by industrial hygienists may also differ, and thus when only one substance was sampled in a situation, there is no guarantee that this was the only substance present in the workplace. More likely, the industrial hygienist sampled only this particular substance because of insurance or regulatory contexts. Finally, not all of the substances present in the databases are listed in MiXie and, likewise, toxicological assessments are not available for all of the substances registered in the COLCHIC and SCOLA databases. Given all of these reasons, it is likely that the number of multiple exposure situations was underestimated in this study.

Despite this limitation, multiple exposure situations were frequently identified, representing $36 \%$ of all situations recorded during the last decade. Multiple exposure may represent more than half of all exposure situations in certain activities such as mixing, moulding, compression, synthesis, calendaring, and laminating, or in tasks performed in companies involved in smelting and printing. In MiXie, a "poorly controlled" situation is defined as a situation in which the El of at least one class of toxicological effects exceeds 1 . Most poorly controlled situations were identified on the basis of the OELV defined for individual substances. However, the tasks most frequently associated with exposure to mixtures of substances were also related to the most frequent observation of poorly controlled situations, and not all of these situations can be identified by single-substance approaches.

The challenge in risk-management is to identify hazards at the outset when defining the riskmanagement plan. Thus, in order to identify the hazards related to multiple exposure, it is important to obtain an exhaustive list of all chemicals present in the workplace. These could be components of products as well as substances emitted during procedures. To reduce the cost of sampling and analysis and to simplify sampling procedures in the field (limiting the number of active samplers placed on workers), new methods of multi-support sampling and analysis have been developed [14].

A qualitative analysis of possible effects should be performed with the help of software such as MiXie. This type of approach would make it possible to identify which mixtures of substances present in the workplace might contribute, through the additive potential of the effects selected, to the creation of a hazardous situation. In light of these results, it will now be possible to better target the substances that should be measured during a sampling campaign.

\section{Conclusion}

In this paper, work situations were analysed from the point of view of multiple exposures to chemicals. If only the OELV of individual components in a mixture are used in a risk assessment, almost $16 \%$ of potentially hazardous situations cannot be detected. With a multiple substance approach, several tasks, related to health, waste-treatment or mixing, are found to present higher 
risks. The chemical-cocktails most frequently associated with a higher risk were cocktails of powders linked to analysis of crystalline silica, mixtures of metals and mixtures of volatile organic compounds.

If multiple exposure is taken into account from the first stages of risk assessment, potentially harmful effects on workers' health could be greatly reduced. The approach used to identify chemical risks should include analysis of substances contained in products as well as those emitted during production procedures. Once all of the substances have been identified, an analysis of their potential effects on health should be performed using an approach such as that implemented in the MiXie software, which will allow the situations that pose the highest risk to workers' health to be highlighted.

\section{Acknowledgements}

We would especially like to thank the Canadian MiXie team for providing initial technical and scientific support: Marc Baril, Daniel Drolet, Naima El-Majidi, François Lemay, Claude Viau and Adolf Viskocil. We also thank the French INRS MiXie team for the OELV adaptation work and for their involvement in the future phases of the project: Stéphane Binet, Pierre Campo, Laureline Coates, Michel Falcy and Florence Pillière. Gautier Mater is thanked for providing the COLCHIC and SCOLA exposure data. Alice Wiiliams is thanked for English translation.

\section{References}

[1] R. Vincent, F. Bonthoux, G. Mallet and J. Iparraguire, "Méthodologie d'évaluation simplifiée du risque chimique : un outil d'aide à la décision," Hygiène et sécurité du travail, 2005.

[2] H. Marquart, H. Heussen, M. Le Feber, D. Noy, E. Tielemans, J. Schinkel, J. West and D. Van der Shaar, "Stoffenmanager', a web-based control banding tool using an exposure process model," vol. 52, no. 6, 2008.

[3] HSE, COSHH essentials: easy steps to control chemicals (second edition), HSE Books, 2002.

[4] INRS, "Seirich : évaluer le risque chimique," [Online]. Available: www.seirich.fr. [Accessed 212 2016].

[5] IRSST, "MiXie : Les mélanges de substances en milieu de travail," [Online]. Available: http://www.irsst.qc.ca/-outil-mixie-les-melanges-de-substances-en-milieu-de-travail-utilitairepour-l-evaluation-du-risque-chimique-calcul-du-rm.html. [Accessed Mai 2014].

[6] Z. Fiala, A. Vyskocil, F. Lemay, J. Kremlacek, L. Borska, D. Drolet, T. Borsky and C. Viau, "Occupational health risk evaluation of exposure to mixtures of chemicals," Toxicology letters, vol. 172, no. 1, 2007.

[7] INRS, “MiXie France," [Online]. Available: www.inrs-mixie.fr. [Accessed 0212 2016].

[8] European Parliament and of the Council, Regulation (EC) No 1272/2008 - classification, labelling and packaging of substances and mixtures, 2008. 
[9] INRS, "SCOLA," [Online]. Available: https://scola.inrs.fr/scola/login.

[10] R. Vincent and B. Jeandel, "COLCHIC - Occupational Exposure to Chemical Agents Database: current content and development perspectives," Applied Occupational and Environmental Hygiene, vol. 16, no. 2, 2001.

[11] G. Mater, C. Paris and J. Lavoué, "Descriptive analysis and comparison of two French occupational exposure databases: COLCHIC and SCOLA," American Journal of Industrial Medicine, vol. 59, no. 5, 2016.

[12] BayesiaLab, "www.bayesia.com," [Online].

[13] F. Craignou and L. Jouffe, "Consumer Driver studies using Bayesian Networks," Sensometrics, 2008.

[14] M. Guillemot, B. Oury and S. Melin, "Identifying thermal breakdown products of thermoplastics," Journal of Occupational and Environmental Hygiene, vol. 14, no. 7, pp. 551-561, 2017.

[15] OSHA, "Indicative Occupational Exposure Limits," 2000/39/EC, 2000.

[16] OSHA, "Indicative Occupational Exposure Limit Values," 2006/15/EC, 2006.

[17] OSHA, “Indicative Occupational Exposure Limit Values," 2009/161/EU, 2009.

[18] Journal Officiel de la République Française, "Arrêté du 15 décembre 2009 relatif aux contrôles techniques des valeurs limites d'exposition professionnelle sur les lieux de travail".

[19] INSEE, "Fiche sectorielle : industrie," in Les entreprises en France, INSEE Références, 2014. 